Academic Platform Journal of Engineering and Science

journal homepage: http://apjes.com/

ACADEMIC

$P L A T F O R M$

\title{
An Investigation of the Deformation Patterns Due to the High-Speed Micro-Laser Drilling Process for Ti-6Al-4V Used in Aerospace Applications
}

\author{
${ }^{* 1}$ Ahu Çelebi, ${ }^{2}$ Halil Tosun, ${ }^{3}$ Ali Caglar Önçağ \\ ${ }^{1}$ Materials Engineering Department, Manisa Celal Bayar University, 45140, Manisa, Turkey, ahu.celebi@cbu.edu.tr, \\ ${ }^{2}$ Materials Engineering Department, Manisa Celal Bayar University, 45140, Manisa, Turkey, haliltosun80@gmail.com, (DD \\ ${ }^{3}$ ESHOT General Directorate, İzmir, Turkey, alicaglar8@ hotmail.com,
}

Research Paper

Arrival Date: 12.06.2019

Accepted Date: 04.03.2020

\begin{abstract}
Hybrid Laminar Flow Control (HLFC) is used in the aviation industry to reduce fuel consumption of civil jet aircrafts. Small holes are required at the leading edges of the aircraft wings and tail planes to reduce friction caused by boundary layer suction. Much research has been made in the application of drilling small holes to Ti-6Al-4V alloys. The most important of these investigations is that the thermal distortion cannot be controlled during the application of a large number of holes in huge areas and thus, it causes deformation as a result of thermal deterioration. When micro drilling is applied, some problems arise due to close proximity of drilled holes. The aim of this investigation is to evaluate the deformation due to the micro laser drilling process and develop an efficient set of certain laser parameters to minimize it. $50 \mathrm{~W}$ power pulsed Ytterbium fiber laser having a galvo scanner have been used during the process. The effects of increased waiting time, use of weight on both sides of the specimens and nitrogen cooling upon the deformation of the drilled samples have been investigated. Before and after the drilling process the samples have been scanned by a 6-axis arm CMM having an integrated 3D laser scanner. The deformation patterns have been obtained with the use of PC-DMIS software. As a result, as the waiting time is increased, less deformation has been observed in the samples. In addition, addition of nitrogen gas to the process has positively influenced the deformation minimization efforts.
\end{abstract}

Keywords: Ti-6Al-4V alloys, Aerospace applications, 3D Laser Scanning, Micro-laser drilling

\section{INTRODUCTION}

The most important reasons why $\mathrm{Ti}-6 \mathrm{Al}-4 \mathrm{~V}$ alloy are preferred especially in aerospace and biomedical applications are high mechanical properties, relatively low density, excellent corrosion resistance and high biocompatibility. In an aircraft structure, the Ti6Al4V alloy, which is particularly difficult to cut metals, is widely used in parts of a gas turbine and medical equipment, and during manufacturing there is a need to connect these parts made of Ti6Al4V alloy and to drill holes for special applications. For example, when a conventional drilling is performed with a twist drill during drilling in a Ti6Al4V alloy, it is very difficult to obtain a highly accurate hole in diameter, roundness and input-output edge quality of the holes due to the low thermal conductivity [1]. The ability to drill holes in micro and small sizes with high aspect ratio in extremely hard and brittle materials, is very important for especially in the field of aerospace (cooling holes in jet turbine blades), space, automobile, electronics and computer (printed circuit boards), medical (surgical implants)[2,3].
Laser drilling is the most widely used method among other drilling techniques. Laser micro drilling is a commonly preferred method for drilling advanced hard or difficult-tocut materials such as ceramic, glass and superalloy composites, and for forming micro-holes in complex shaped parts ) [4,5].

One of the major engineering challenges with Hybrid Laminar Flow Control (HLFC) is the design and manufacture of the suction surface. As part of the laminar flow control study that began in the 1940s, various ways of producing a skin surface that would allow the absorption of air were investigated. The improved suction surfaces, which are bores punched by electron or laser beam, are divided into different categories. Laser drilling has been a preferred technique since the mid-1980s [6]. Electrical Discharge Processing (EDM) is another common method used to drill titanium alloys. The biggest problem encountered in micro EDM drilling is the removal of residual particles, so electrode rotation is preferred to overcome this problem [7, $8]$. 
The combination of impact peak strength and duration significantly affects the material removal mechanism in the laser drilling process. In a study, micro-hole drilling using nanosecond pulses is generally reported to be worse than EDM because of melting, although generally metals produce acceptable quality holes $[9,10]$.

Laser drilling is generally preferred for three main processes. The first is the laser cleaning process. In this process, the laser beam is rotated in a circular way and cuts the perimeter of the hole $[10,11]$. It is a laser cutting process rather than drilling. The second is laser single-pulse laser drilling, where all material is removed with a single pulse [12]. Particularly preferred in low thickness parts having an aspect ratio of 1:10 and drilling holes. Finally, it is a laser pulse drilling process which is based on the removal of the material by a series of pulses. Each pulse removes a certain volume of material, so that all pulse sequence diameters can achieve holes with depths ranging from 25 to $500 \mu \mathrm{m}$ [13].

Prior work has amply revealed that optimizing the laser parameters such as aver-age power, pulse energy, pulse duration, pulse frequency, focal position etc. can possibly provide a means for minimizing the drilling defects [14, 15]. Yilbas [16] has shown that the extent of taper formation during laser percussion drilling of thin sections can be significantly reduced by suitable control of laser variables. Studies by Yeo et al. [17] and results reported by Chen et al. [18] indicate that an excessively long pulse duration or a very high pulse energy can both lead to deformation of parent material structure as well as adversely influence taper and recast layer formation. Other research efforts have established that a shorter pulse duration minimizes the recast layer and reduces micro-cracking at the side-walls of the laser drilled hole $[19,20]$, with a pulse duration of $0.1-2.5 \mathrm{~ms}$ being proposed as being most suitable for deep hole drilling [17]. There has also been an initiation of efforts aimed at tailoring the pulse pattern to enhance hole quality and this has yielded encouraging results [21-23]. Bandyopadhyay [24] et al. have studied Nd:YAG laser drilling of 4 and $8 \mathrm{~mm}$ thick sections of IN718 and Ti-6Al-4V materials. The influence of type of material and its thickness, as well as parametric impact of key process variables like pulse frequency and pulse energy, have been determined. Oxygen and nitrogen were employed as assist gases during processing of IN718 and $\mathrm{Ti}-6 \mathrm{Al}-4 \mathrm{~V}$, respectively. The hole characteristics observed during $\mathrm{O}_{2}$-assisted drilling of IN718 are substantially different from those noted in $\mathrm{N}_{2}$-assisted drilling of $\mathrm{Ti}-6 \mathrm{Al}-4 \mathrm{~V}$. Results suggest that, for sheets of similar thickness drilled employing identical laser parameters, the IN718 material yields holes with a finer size, lower taper, less spatter and reduced recast layer as compared to $\mathrm{Ti}-6 \mathrm{Al}-4 \mathrm{~V}$ [24].

When a laser beam strikes the material, thermal interaction occurs on the surface of the workpiece, creating the heat- affected zone (HAZ). Due to the high temperature of the laser beam, the physical, mechanical and chemical properties of the workpiece change in the interaction area.

HAZ is the area of work material that does not melt during laser machining but has an effect on microstructures. The depth of the HAZ zone during laser machining is one of the important metallurgical performance characteristics [25] so, one of the main problems in percussion laser drilling is the deformation due to temperature caused by laser [26]. Due to focused beam energy on the surface of a workpiece during laser drilling, melting and evaporation take place. In this process, thermal residual stresses occur as tension and compression (Fig. 1) due to the amount of absorbed energy, the cooling rate, temperature gradient and contraction in the hole and the HAZ (Heat Affected Zone) [27, 28].
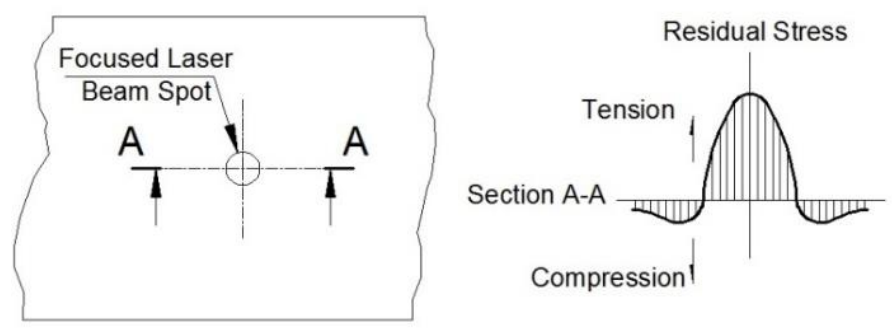

Fig. 1. Residual stress after laser processing.

The presence of a heat-affected zone (HAZ) constitutes the most important of the metallurgical defects associated with micro-drilling. This occurs when the laser processing scanner is subjected to severe thermal cycles during which this region is affected by heat [29]. The distortion of the sheets is influenced by the applied that thermal cycles and energy input during laser processing. The main objective of this work is to determine the distortion amounts of the laser drilling process due to the fabrication of suction surfaces on Ti-6Al-4V alloy sheet using $50 \mathrm{~W}$ pulse fiber laser. While drilling micro holes, impact of increased waiting times, use of weight on both sides of the specimens and use of cooler nitrogen gas environment upon deformation modifications were investigated via a 3D laser scanner integrated to a portable-arm Coordinate Measurement Machine (CMM) and PC-DMIS software.

\section{EXPERIMENTS/TESTS}

\subsection{Materials and Methods}

$0,8 \mathrm{~mm}$ Ti-6Al-4V sheet has been used for the experiment. Chemical composition of this titanium alloy sheet is given in Table 1. There are three main phases in the experiments. First one is laser drilling operations under different conditions and variations, the second is measuring the deformation amounts occurred because of the drilling operations. So as to obtain the differences of deformation before and after drilling operations specimens should have been scanned by a 3D scanner. A flowchart has been followed for all operations. 
Table 1. The composition of Ti6Al4V (wt \%)

\begin{tabular}{|c|c|c|c|c|c|c|c|}
\hline Material & $\mathrm{Ti}$ & $\mathrm{Al}$ & V & $\mathrm{Fe}$ & $\mathrm{Si}$ & $\mathrm{H}$ & $\mathrm{O}$ \\
\hline Content & Balance & $\begin{array}{c}5.5- \\
6.8\end{array}$ & $\begin{array}{c}3.5- \\
4.5\end{array}$ & $<0.3$ & $<0.15$ & $<0.015$ & $<0.2$ \\
\hline
\end{tabular}

The flowchart of the experiments is given in Fig. 2. to explain the sequence of the operations. The third phase of the experiment is the suction surface inspection of the drilled specimens with a digital microscope. Three methods and their combination have been tried to control and prevent thermal distortion. Firstly, it was aimed to prevent deformation and increase heat dissipation by weights placed on both sides of Ti alloy sheets in scan area. Secondly, the waiting time has been increased between the two pulses so that sheet is mostly uniformly heated. This is performed by drilling hole-pattern with 0,490 and 980 milliseconds waiting time. Finally, Nitrogen has been used because it is thought to be a cooling effect and may reduce the thermal distortion.

Materials to be used in the experiments,

- Ti-6Al-4V sheets

- 1064 nm Nufern 50 W Q-Switched Pulse laser machine for drilling

- HP-L.8.9 3D laser scanner integrated to Romer 7320 portable CMM

- $\quad$ PC-DMIS software to obtain the scanning results DinoLite digital microscope to inspect the surface of the drilled specimen.

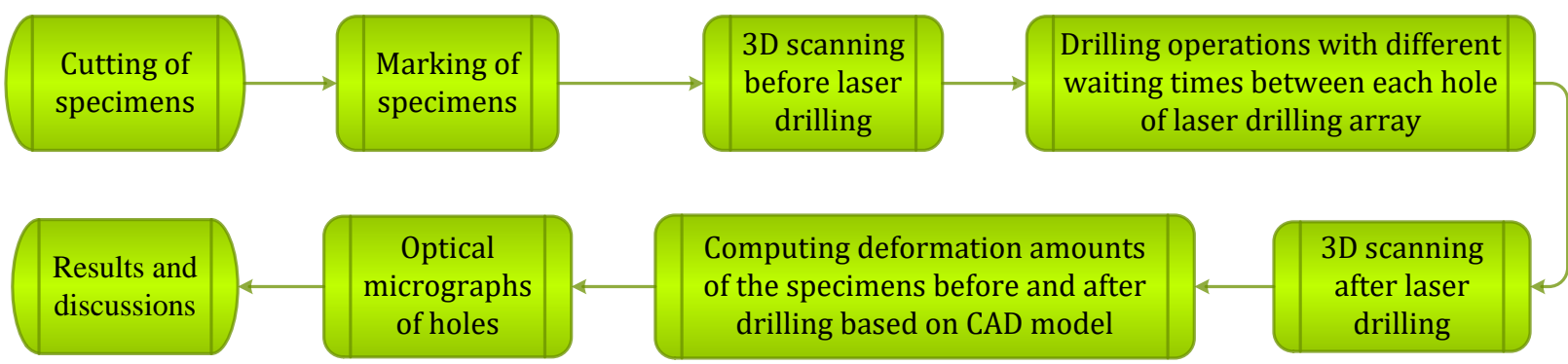

Fig.2. Flowchart of the experiments

All specimens which will be drilled by laser, have been scanned to inspect deformation amounts. HP-L.8.9 3D laser scanner (Fig. 3 and Table 2) integrated to Romer 7320 portable CMM and PC-DMIS software have been used for acquiring data as point clouds. CAD model of the specimens has been imported to PC-DMIS and used as the reference for all 3D scanning operations.

Nufern Q-Switched Pulse laser has been used in micro drilling operations. The laser used is Ytterbium fiber laser. This laser is capable of operating at a maximum output power of $50 \mathrm{~W}$ at $1064 \mathrm{~nm}(\lambda)$ wavelength in basic Gauss mode and is used for pulse processing up to $200 \mathrm{kHz}$. A galvanometer scanner has been integrated to the laser source for laser processing.

DinoLite digital microscope has been used to observe the surface of the holes with two different magnifications. Diameters of the holes and the distance between the holes have been measured with the software of microscope.

\subsection{Preparation of Specimens for Laser Drilling}

Specimen dimensions have been chosen as $165 \times 40 \times 0,8 \mathrm{~mm}$. CAD model have been designed as properly with Autodesk Inventor. After preparing the CAD model Ti-6Al-4V sheet has been cut by laser machine. Laser marking has been applied to all specimens in order to distinguish and to track the results of different operations.

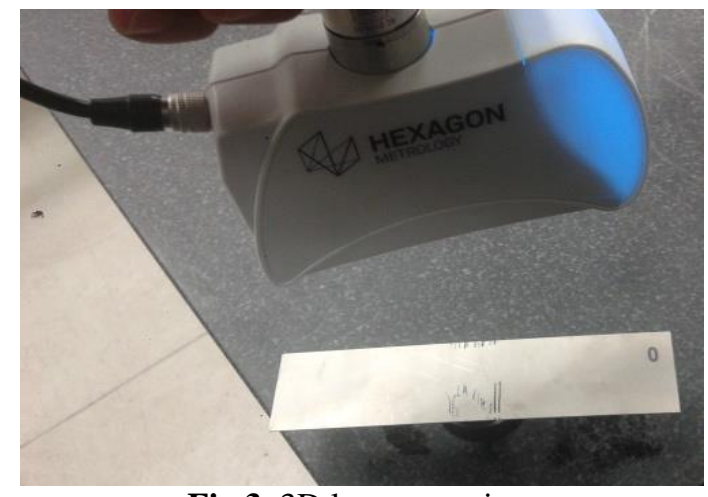

Fig.3. 3D laser scanning.

Table 2. Specification of HP-L.8.9 3D laser scanner [30].

\begin{tabular}{|l|l|}
\hline Accuracy & $40 \mu \mathrm{m} 2$ sigma \\
\hline Point acquisition rate & 45000 points per \\
\hline Points per line & 750 \\
\hline Line rate & $60 \mathrm{~Hz}$ \\
\hline Line width (mid-field) & $80 \mathrm{~mm}$ \\
\hline Stand-off distance & $135 \mathrm{~mm}+/-45 \mathrm{~mm}$ \\
\hline Minimum point spacing & $0,08 \mathrm{~mm}$ \\
\hline Laser power adjustment & Semi-automatic \\
\hline
\end{tabular}

\subsection{Scanning Specimens Before and After Laser Drilling}

After scanning of each non-drilled specimen, the acquired point clouds have been aligned to CAD model to inspect 
deformation amounts. The acquired point clouds give distortions due to the preparation of the specimens (Fig.4(c). Fig. 4 shows scanning operation, Fig. 4(a) and (b) show alignment of CAD model and point cloud. After laser micro drilling, the specimens scanned before having been scanned with the same technique again. CAD and point cloud comparison after alignment and distortions of a specimen after laser drilling is shown in Fig. 4(d).

\subsection{Laser Drilling}

During the process, the laser beam is delivered via an accurately programmable galvanometer scanner on the target panel at high speeds of up to $3 \mathrm{~m} / \mathrm{s}$, with a lateral resolution of $1 \mu \mathrm{m}$. The orthogonal arrangement of the mirrors $\mathrm{X}$ and $\mathrm{y}$ directs the beam towards the workpiece along the length and width of the scanning piece.

Laser spot size here can be calculated using the formulation:

$\mathrm{d}_{0}=\mathrm{M}^{2} \cdot 4 \cdot \lambda \cdot \mathrm{f} /\left(\pi \cdot \mathrm{D}_{0}\right)$,

Where $\mathrm{d}_{0}$ is the focused spot diameter, $\mathrm{f}$ is the focal length of the focusing lens, $\mathrm{D}_{0}$ is the input beam diameter and $\lambda$ is the laser beam wavelength, $\mathrm{M}$, is the beam mode [31].

The laser and all equipment's of it have been mounted to a construction and all micro laser drilling operations (Fig.5(b). have been carried out on this construction (Fig.5(a). Laser drilling operations have been performed with software called EzCAD as integrated to the laser. During the laser drilling operations an aluminum plate has been mounted to the construction and has been used under the specimens (Fig.5(b). Laser beam that is utilized in laser drilling operation has average pulse energy of $1 \mathrm{~mJ}$. In operations, 50 $\mathrm{kHz}$. as the repetition rate has been chosen for maximum power. Laser power can be calculated from this equation:

Power $=$ Work $/$ Time $\mathrm{P}=\mathrm{W} / \mathrm{t}$

It is seen that maximum pulse energy can be achieved at this repetition rate $\left(50 \mathrm{~W}=1 \mathrm{~mJ} X 50000 \mathrm{~s}^{-1}\right)$. In the equation, Where $\mathrm{P}$ is the power, $\mathrm{W}$ is work and $\mathrm{t}$ is time.

There is more than one hole for each specimen and a drilling array has been designed for the drilling operations. In laser drilling, different variables have been tried. The waiting time refers to the time between two holes without laser pulses. Three different waiting times between each hole of array have been used during laser drilling operations for different specimens. Specified parameters have been determined by considering previous studies. These are 0 milliseconds, 490 milliseconds and 980 milliseconds. In addition to waiting times, Nitrogen gas and weight have been used for some specimens as the other variables (Fig. 6). The dimensions of the array are shown in Fig.7 and have been determined as according to the aerospace industry's needs.

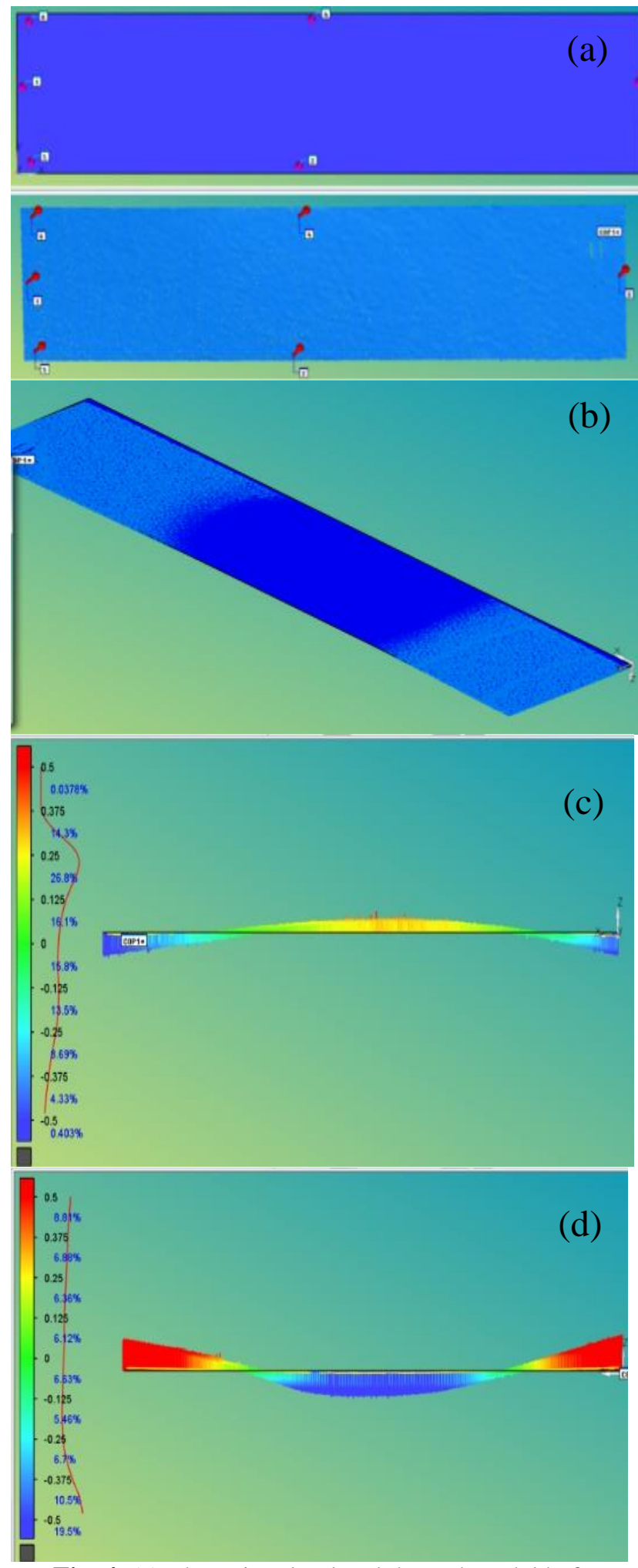

Fig. 4. (a) The point cloud and the cad model before alignment (b) the point cloud and the cad model after alignment (c) the distortions of the point cloud of the specimen before laser drilling (d) the distortions of the point cloud of the specimen after laser drilling (specimen code: 4a). 

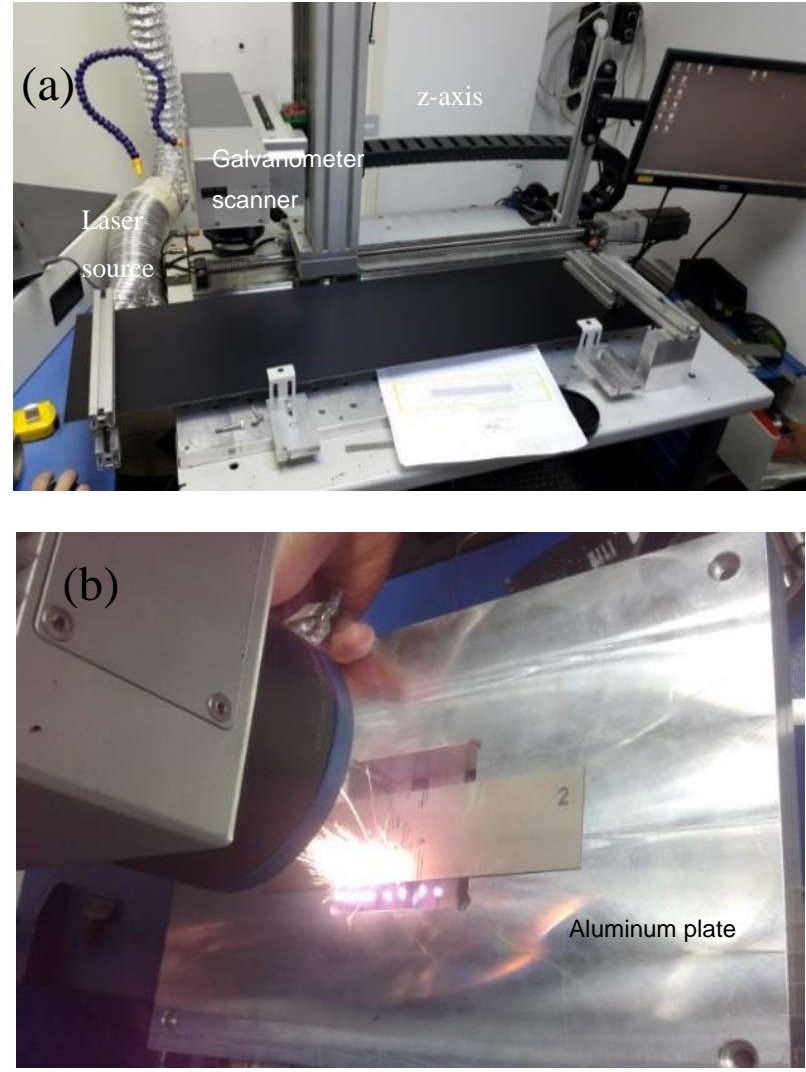

Fig.5. (a) Laser as mounted to the construction, (b) Laser micro hole drilling.
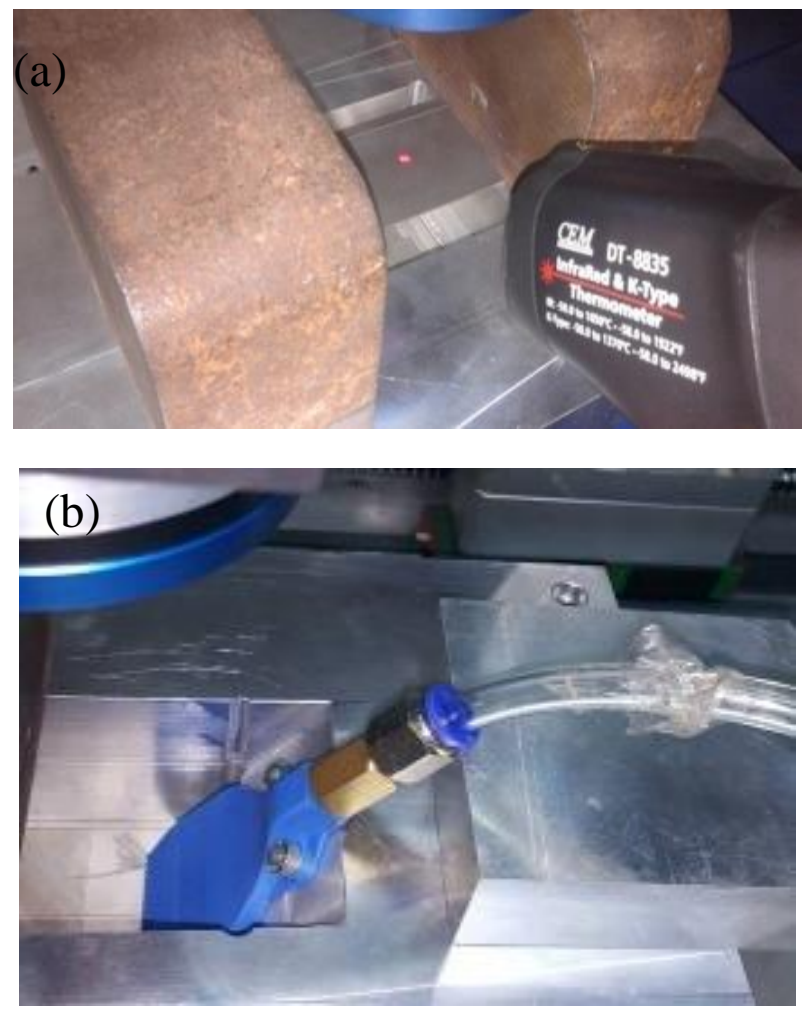

Fig.6. a) Use of weight on both sides of the specimen b) Gas feeding mechanism used for test
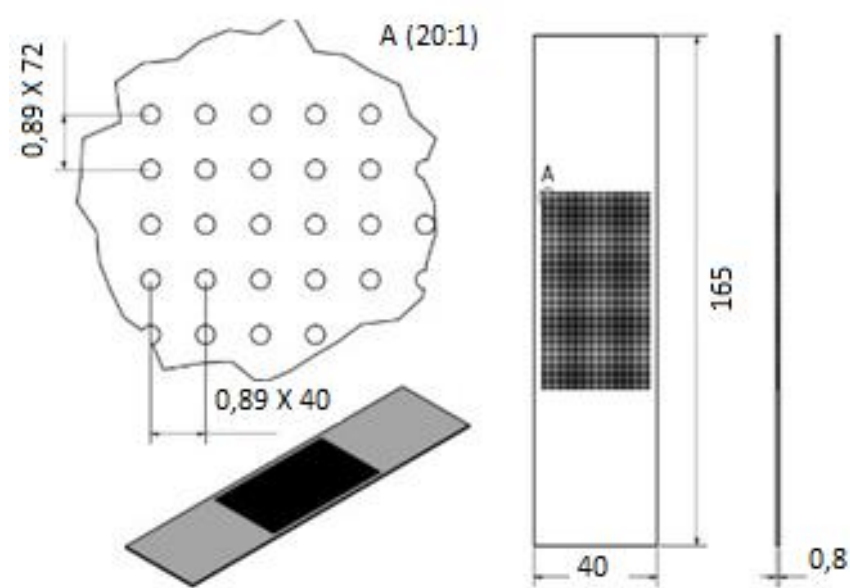

Fig. 7. Drilling array.

Six different samples were analyzed in 2 replicates. The variables of laser drilling operations and specimen codes (marks) have been given in Table 3. As shown in Table 3, values in the same color indicated repeated samples. Nitrogen gas has been used because it is thought to be a cooling effect and may reduce distortions. Weight has been used for similar reason like Nitrogen. So-called laser marked specimens have chosen randomly in drilling operations.

Table 3. Variables of laser drilling operations.

\begin{tabular}{|c|c|c|c|c|}
\hline $\begin{array}{l}\text { Specimens } \\
\text { Code } \\
\end{array}$ & $\begin{array}{l}\text { Waiting Time } \\
\text { (msec.) }\end{array}$ & $\begin{array}{l}\text { Cooler Nitrogen } \\
\text { Gas (0.5 bar) }\end{array}$ & In Air & $\begin{array}{l}\text { Using } \\
\text { Weight } \\
\end{array}$ \\
\hline 1a & 0 & - & $X$ & - \\
\hline $1 b$ & 0 & - & $X$ & - \\
\hline $2 a$ & 0 & $X$ & - & - \\
\hline $2 b$ & 0 & $X$ & - & - \\
\hline $3 a$ & 490 & - & $X$ & - \\
\hline $3 b$ & 490 & - & $X$ & - \\
\hline $4 a$ & 490 & $X$ & - & - \\
\hline $4 b$ & 490 & $X$ & - & - \\
\hline $5 a$ & 490 & - & $X$ & $X$ \\
\hline $5 b$ & 490 & - & $X$ & $X$ \\
\hline $6 a$ & 980 & - & $X$ & - \\
\hline $6 b$ & 980 & - & $X$ & - \\
\hline
\end{tabular}

\section{RESULTS and DISCUSSIONS}

The coordinate measuring machine (CMM), which will be used to examine the shape and obtain the point data of the shape, is widely preferred especially in aerospace and manufacturing engineering because it provides high accuracy and versatility. The micro drilling sheets were scanned with a laser scanner (HP-L.8.9) to observe the difference in deformation after micro drilling. These Ti6Al4V sheets, micro drilled and drawn by CAD program, was overlapped, and preliminary prepared for sectioning. In order to measure the deformation of the laser micro drilling, the deviations from 4 different points were recorded using 
the PC-DMIS program, and deformation of the laser micro drilling was observed.

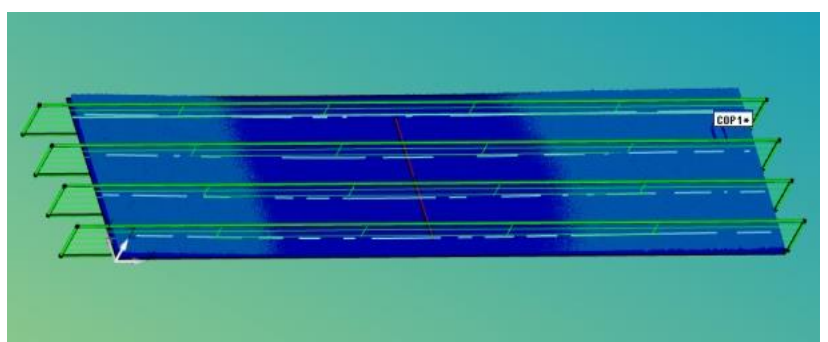

Fig.8. Cad model point cloud (COP-Cloud of Point)) and sections (The distance between the sections are $10 \mathrm{~mm}$ ).

Beside the whole point cloud comparison inspection, Sections have been created in PC-DMIS and deviation amount of point clouds in the sections have been measured (Fig. 8).

When compared distortion amounts of a specimen before and after laser drilling, remarkable distortion has been observed after drilling. It can easily detect that distortion amounts of Fig.4(d) are higher than Fig.4(c). Despite that the deviation values between $0-0.25 \mathrm{~mm}$ are about $25 \%$ after drilling in Fig. 4(d), it is seen from Fig.4(c) that deviation values of $\% 75$ of points are between $0-0,25 \mathrm{~mm}$. In addition, although Fig. 4 (c) shows that the deviations of approximately all the points are in the range of $0-0.5 \mathrm{~mm}$, the specimen has been distorted after drilling and the deviations of the points in the range of $0-0.5 \mathrm{~mm}$ have been remained at $50 \%$ (Fig. 4(d)). The distortions in red and dark blue regions showed in the Fig.4(c) and Fig.4 (d) are higher and in the green regions are lower.

Table 4. Differences of deviation values of the specimens before and after laser drilling.

\begin{tabular}{|c|c|c|c|c|c|c|c|c|}
\hline \multicolumn{4}{|c|}{$\begin{array}{l}\text { Max. Deviations in Sections (mm) } \\
\text { (Before Laser Drilling) }\end{array}$} & \multirow[t]{2}{*}{$\begin{array}{l}\text { Specimen } \\
\text { Code }\end{array}$} & \multicolumn{4}{|c|}{$\begin{array}{l}\text { Max. Deviations in Sections (mm) } \\
\text { (After Laser Drilling) }\end{array}$} \\
\hline Section 1 & Section 2 & Section 3 & Section 4 & & Section 1 & Section 2 & Section 3 & Section 4 \\
\hline 0.866 & 0.882 & 0.865 & 0.949 & $1 \mathrm{a}$ & 2,411 & 2,253 & 2,430 & 2,121 \\
\hline 0.770 & 0.738 & 0.737 & 0.720 & $1 b$ & 2.054 & 2.329 & 2.216 & 1.742 \\
\hline 0.904 & 0.897 & 0.871 & 0.722 & $2 \mathbf{a}$ & 2.292 & 2.445 & 2.412 & 1.772 \\
\hline Error & Error & Error & Error & $2 b$ & Error & Error & Error & Error \\
\hline 0.778 & 0.653 & 0.735 & 0.764 & $3 \mathbf{a}$ & 1.473 & 1.610 & 1.435 & 1.367 \\
\hline 0.753 & 0.878 & 0.804 & 0,737 & $3 b$ & 1.947 & 1.702 & 1.560 & 1.524 \\
\hline 0.808 & 0.794 & 0.743 & 0.724 & $4 a$ & 1.177 & 1.455 & 1.428 & 1.410 \\
\hline 0.784 & 0.835 & 0.824 & 0.807 & $4 b$ & 1.370 & 1.547 & 1.449 & 1.447 \\
\hline 0.774 & 0.708 & 0.663 & 0.727 & $5 \mathbf{a}$ & 1.616 & 1.726 & 1.672 & 1.330 \\
\hline 0.720 & 0.752 & 0.731 & 0.765 & $5 b$ & 1.319 & 1.451 & 1.476 & 1.470 \\
\hline 0.782 & 0.632 & 0.852 & 0.793 & $6 a$ & 1.488 & 1.709 & 1.723 & 1.747 \\
\hline 0.734 & 0.760 & 0.824 & 0.807 & $6 b$ & 1,417 & 1,481 & 1,347 & 1,574 \\
\hline
\end{tabular}

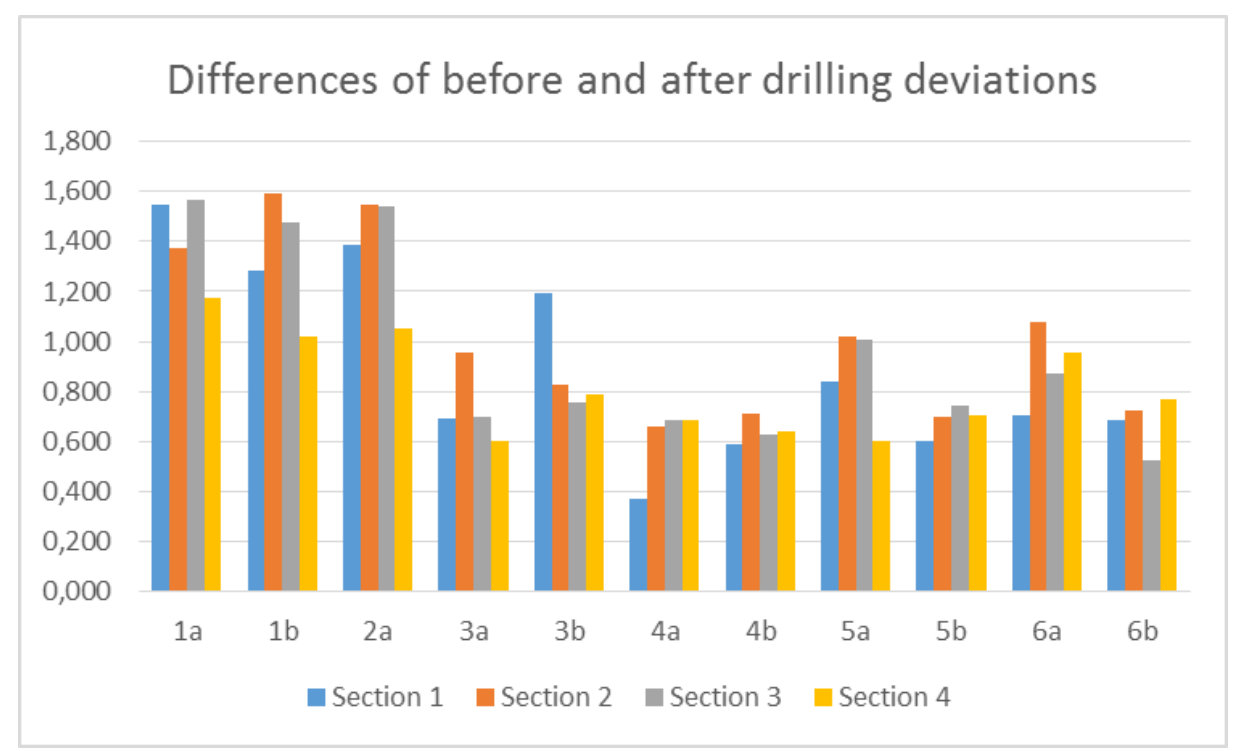

Fig.9. Differences values of before and after drilling deviation 
The increase in waiting time can be explained by the fact that the decrease in distortion is due to the less uniformity of heat density. The nitrogen gas application for cooling was slightly decreased deviation between the sections for $4 \mathrm{a}$ and $4 \mathrm{~b}$. While nitrogen gas application without any waiting period did not provide an improvement in deformations, nitrogen gas applied when waiting time was 490 milliseconds had a slightly positive effect on differences values of before and after drilling deviations as shown Fig 9. In addition, if the waiting time is increased from 490 milliseconds to 980 milliseconds $(6 a, 6 b)$, there is no decrease on differences of before and after drilling deviations as when the waiting time rises from 0 milliseconds to 490 milliseconds. This shows that the prolongation of the waiting times does not affect the deformation after a positive effect up to a certain point.

When images of the digital microscope are examined, spatter formations have been detected around the periphery of the holes as inherent defects of laser drilling (Fig 10 a, b).

Shock waves generated by laser beam are seen with blue lines. If the laser application is continuous, the workpiece is affected by more shock waves because it melts and perforates the material. Thus, a larger HAZ region is formed. The area affected by the heat is seen in black. The radius of the different holes is similar (Fig $10 \mathrm{a}, \mathrm{b}$ ) and the distance between the holes. Fig.10 (c) is appropriate to drilling array given in Fig.7. Positions of the holes are quite accurate.

The color map of before and after drilling each sample micro-drilled is given in Figs 11 and 12. When these color maps were examined, results have been obtained in a way that confirms the deviation values of sections. Particularly, in Figure 11.h, 12.b and 12.d, it is seen that in the specimens $4 \mathrm{~b}, 5 \mathrm{~b}$ and $6 \mathrm{~b}$ after the micro drilling process, the sheet less deformed than the case before it was micro drilled. In Figures 11.a and $\mathrm{b}$, the deviation value of specimen $(0.5 \mathrm{~mm}) 15$ is $0.243 \%$, while the deviation value in this range is $27.6 \%$. Therefore, it is observed that deformation is found most in this sample where the waiting time is 0 .

As mentioned in the literature, because of the higher heat input that resulted in a wider HAZ, deviation between the sections has increased more. When weight applied on the sheets, nitrogen gas application for cooling and the waiting time is increased; deviation between the sections has been decreased because of the lower heat input and consequently narrower HAZ. As a result, distortion of the specimens may come about, and excessive thermal residual stresses induced in sheets during and after laser drilling due to the difference in cooling rates and thermal shrinkage between the surface and interior regions of the material.
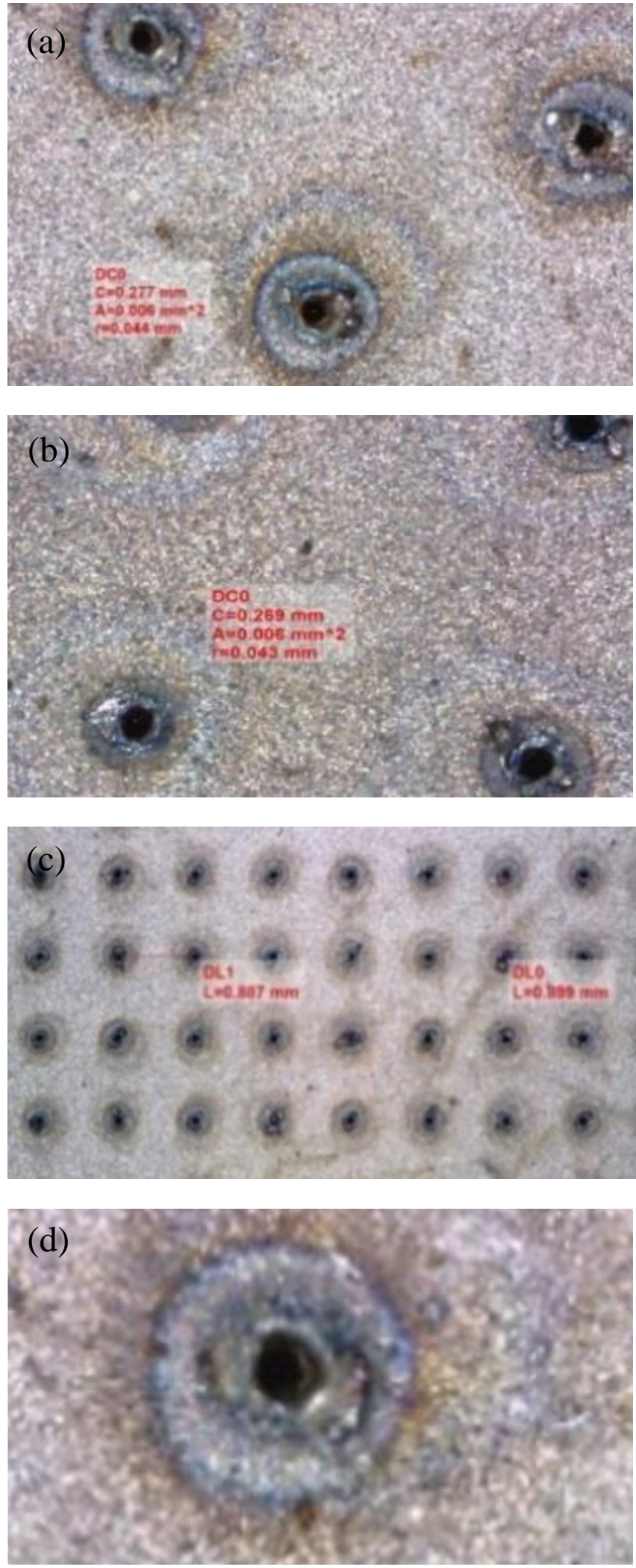

Fig.10. Images of suction surfaces; hole distance $0.89 \mathrm{~mm}$, beam entrance side (a) specimen code: $2 \mathrm{a}$, zoom: $229.5 \mathrm{X}$

(b) specimen code: $4 \mathrm{a}$ zoom: $229.5 \mathrm{X}$ (c) specimen code: $2 \mathrm{a}$ zoom: $51 \mathrm{X}$ (d) specimen code: $2 \mathrm{a}$ (r: radius of the circle, L: length, A: area, $\mathrm{C}$ : circumference 

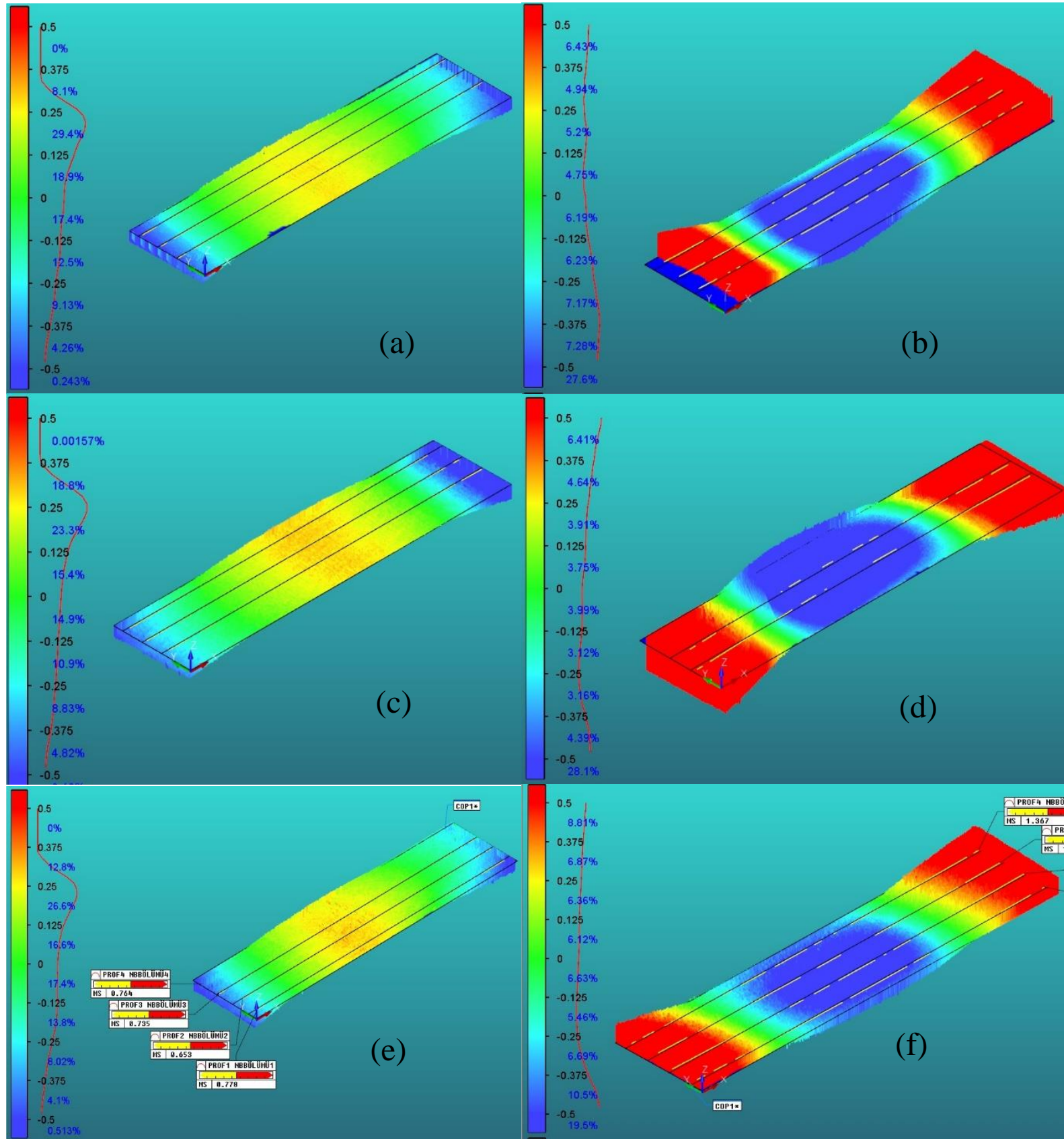

(d)
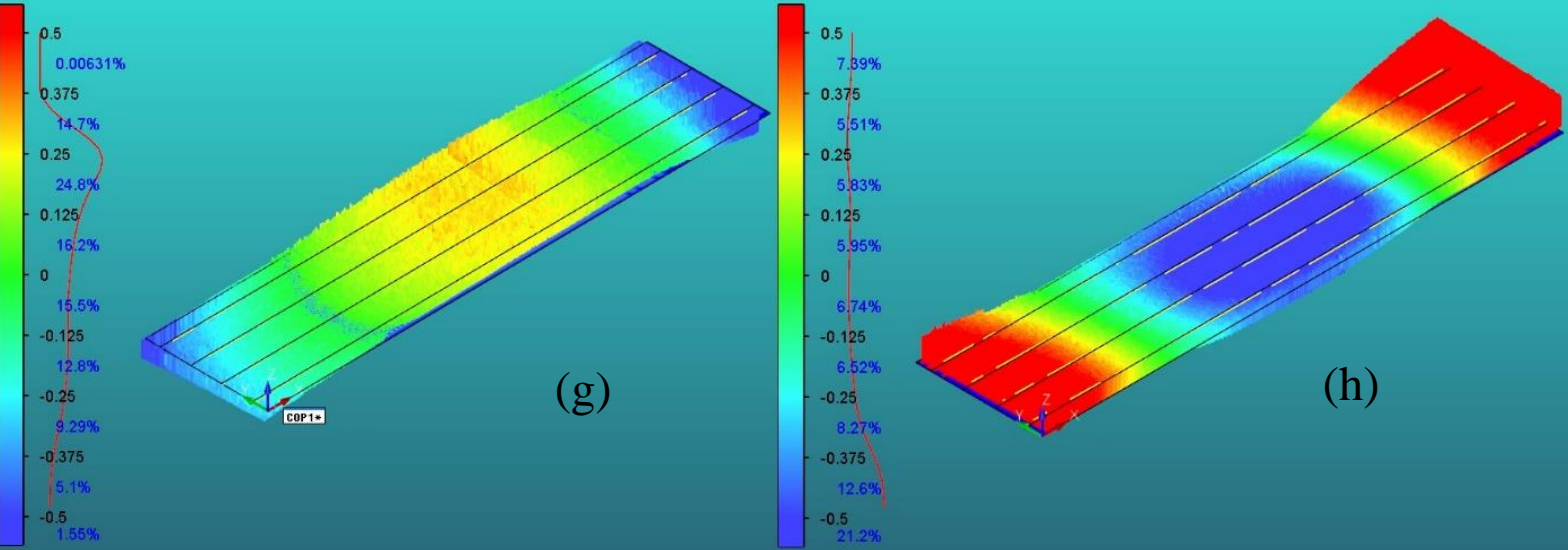

Fig. 11. Color maps of before (a) Specimen $1 b$ (c) Specimen 2a (e) Specimen 3a (g) Specimen 4b, and after (b) Specimen $1 b$ (d) Specimen 2a (f) Specimen 3a (h) Specimen $4 \mathrm{~b}$ micro-drilling process 

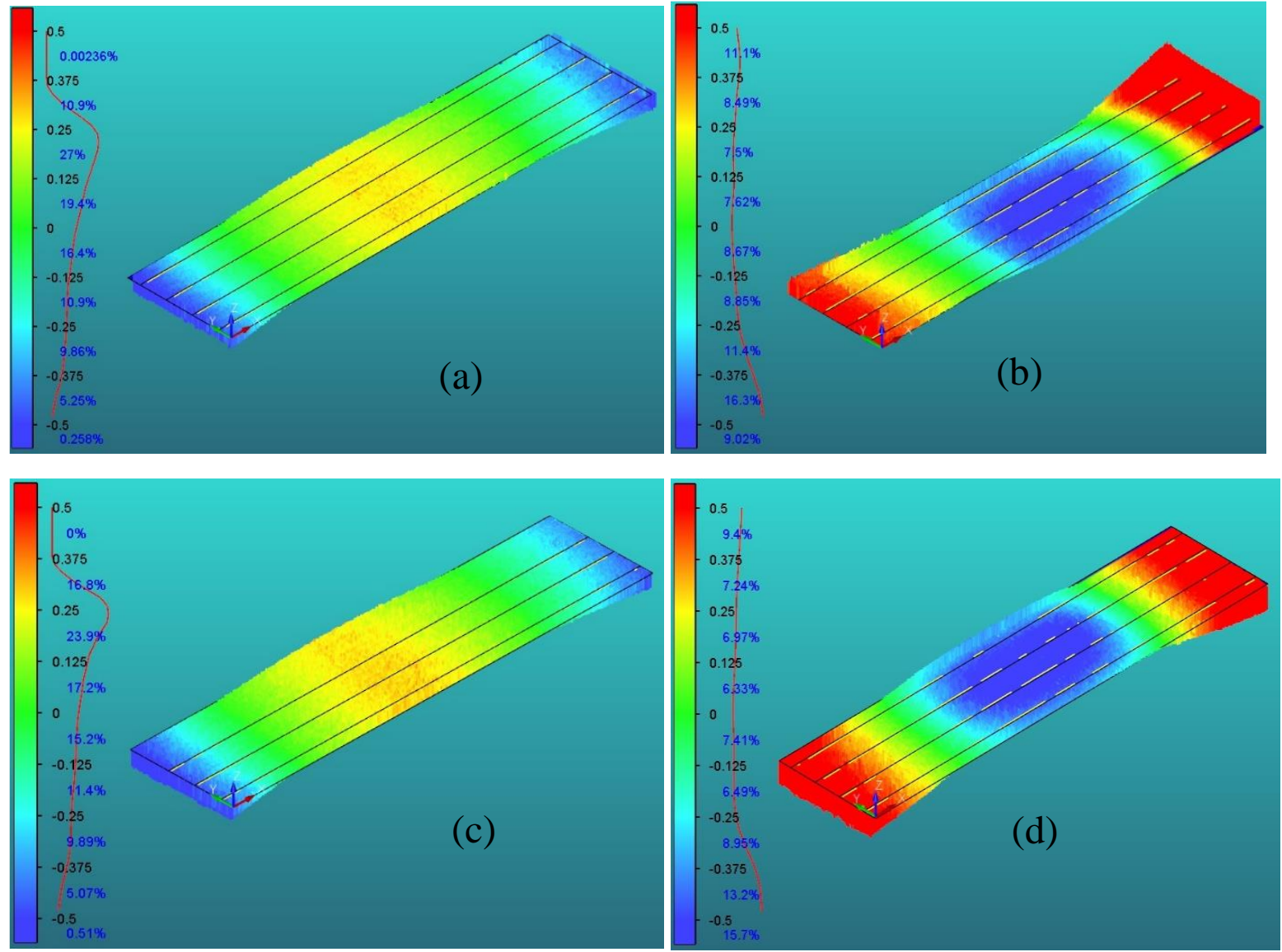

Fig. 12. Color maps of before (a) Specimen $5 b$ (c) Specimen 6b, and after (b) Specimen $5 b$ (d) Specimen 6b micro-drilling process

\section{CONCLUSION}

The obtained results demonstrated use of waiting time decreases the distortion amounts while drilling. Without waiting time between drilling of each holes, the energy absorbed by the workpiece at per unit time becomes more and the distortions become more due to the non-uniform temperature increases. Optimum waiting time values can be found out with more tests. It is possible to detect easily the distortion amounts with 3D laser scanner after laser drilling. 3D laser scanners and quality control software are useful in order to control the appropriateness of the laser drilling parameters. It should be considered while evaluating the results; some distortions might be occurred because of preparing the specimens before laser drilling. A more comprehensive study to model the effect of these parameters with mathematical functions still needs to be done.

Considering Fig 9, 10, 11 and Table 4, the following can be said:

- A significant amount of distortion occurs due to heat input during laser drilling.

- Without waiting time distortions are the highest and Nitrogen gas has no effect on it.

- It is possible to restrain the non-uniform temperature increase in the part during drilling thanks to waiting time between two pulse, so that between holes decrease distortion amounts.

- Increasing waiting time between holes decrease distortion amounts.

- The use of nitrogen gas for the 490-milliseconds waiting time reduces the distortions in small quantities.

- The use of weight has no remarkable effect on distortions when waiting times are 490 milliseconds.

- When compared no waiting time, choosing 490 milliseconds or 980 milliseconds reduce the distortion amounts.

By applying thermal finite element analysis, its results can be compared with the results of the experiments. It can be observed whether different results will be obtained or not for practicing on larger specimens.

\section{ACKNOWLEDGEMENTS}

The authors gratefully acknowledge the support of the LASERAL.

\section{REFERENCES}

[1] H. Yagishita, J. Osawa, "Highly accurate hole making technology of Ti6Al4V by orbital drilling: Effect of oil mist ", Procedia Manufacturing, vol 5, pp. 195-204, 2016. 
[2] M. Sen, H. S. Shan, "A review of electrochemical macroto micro-hole drilling processes", International Journal of Machine Tools and Manufacture, vol. 45, no 2, pp. 137-152, 2005.

[3] M. C. Kayacan, Y. B. Baykal, T. Karaaslan, K. Özsoy, İ. Alaca, B. Duman,, Y. E\& Delikanl,, "Monitoring the osseointegration process in porous Ti6Al4V implants produced by additive manufacturing: an experimental study in sheep", Journal of Applied Biomaterials \& Functional Materials, vol 16, no. 2, pp. 68-75, 2018.

[4] H. Huang, L.-M. Yang ve J. Liu, "Huan Huang,, Lih-Mei Yang, and Jian Liu", Micro-hole drilling and cutting using femtosecond fiber laser, vol. 3, no 53, 2014.

[5] C.Y. Wu, C.W. Shu, Z.C. Yeh, "Effects of excimer laser illumination on microdrilling into an oblique polymer surface", Optics and Lasers in Engineering, vol. 44, no 8, pp. 842-857, 2006.

[6] T. M. Young, B. Humpherys, J. P. Fielding, "Investigation of hybrid laminar flow control (HLFC) surfaces", Aircraft Design, vol 4, no 2-3, pp. 127-146, 2001. [7] S. U. S., P. S. Jagtap, "Optimization of micro EDM drilling process parameters for titanium alloy by rotating electrode", Procedia Manufacturing, vol. 20, pp. 119-126, 2018.

[8] G. Casalino, A.M. Losacco, A. Arnesano, F. Facchini, M. Pierangeli, C. Bonserio, "Statistical analysis and modelling of an Yb: KGW femtosecond laser micro-drilling process", Procedia CIRP, vol. 62, pp. 275-280, 2017.

[9] L. Li, C. Diver, J. P Atkinson, R. Giedl-Wagner, H. J. Helml, "Sequential laser and EDM micro-drilling for next generation fuel injection nozzle manufacture", CIRP Annals, vol. 55, no 1, pp. 179-182, 2006.

[10] J. Tu, A. G. Paleocrassas, N. Reeves ve N. Rajule, "Experimental characterization of a micro-hole drilling process with short micro-second pulses by a CW singlemode fiber laser", Optics and Lasers in Engineering, vol. 55, pp. 275-283, 2014.

[11] D. Ashkenasi, T. Kaszemeikata, N. Muellera, R. Dietrich, "Laser trepanning for industrial applications", Physics Procedia, vol. 23, no Part B, pp. 323-331, 2011.

[12] W. Schulz, U. Eppelt ve R. Poprawe, "Review on laser drilling I. Fundamentals, modeling, and simulation", Journal of Laser Applications, vol. 25, no 1, 2013.

[13] I. Arrizubieta, A. Lamikiz, S. Martínez, E. Ukar, I. Tabernero, F. Girotab, "Internal characterization and hole formation mechanism in the laser percussion drilling process", International Journal of Machine Tools and Manufacture, vol. 75, pp. 55-62, 2013.

[14] S.C. Tam, C.Y. Yeo, R. Willams, L.J. Yang, S. Jana, L.E.N. Lim, M.W.S. Lau, Y.M. Noor, "Optimization of laser deep-hole drilling of Inconel-718 using the Taguchi method", J. Mater. Process. Technol., vol. 37 pp. 741-757, 1993.

[15] W.K. Hamoudi, B.G. Rasheed, "Parameters affecting Nd:YAG laser drilling of metals", Int. J. Joining Mater., vol. 7, pp. 63-69, 1995.

[16] B.S. Yilbas, "Parametric study to improve laser hole drilling process", J. Mater. Process. Technol., vol. 70, pp. 264-273, 1997.

[17] C.Y. Yeo, S.C. Tam, S. Jana, M.W.S. Lau, " A technical review of the laser drilling of aerospace materials", J. Mater. Process. Technol., vol. 42, pp. 15-49, 1994.

[18] X. Chen, X. Liu, W.T. Lotshaw, "Machining with ultrashort laser pulses", ICALEO E, pp. 64-7, 1996.

[19] T.J. Rockstroh, X. Chen, W.T. Lotshaw, "Influence of laser pulse duration on laser drilled hole quality in nickel based super alloy", ICALEO C, pp. 113-122, 1996.

[20] X. Chen, W.T. Lotshaw, A.L. Ortiz, P.R. Staver, C.E. Erikson, M.H. Mclaughlin, T.J. Rockstroh, "Laser drilling of advanced materials: Effects of peak power, pulse format, and wavelength", J. Laser Appl., vol. 8, pp. 233-239, 1996.

[21] S.O. Roos, "Laser drilling with different pulse shapes", J. Appl. Phys., vol. 51, pp. 5480-5485, 1980.

[22] D.K. Low, L. Li, P.J. Byrd, "Taper control mechanism and taper control during laser percussion drilling of $\mathrm{Ni}$ alloy", Proceedings of the 33rd International Matador Conference, Springer, London, 913-921, (2000).

[23] D.K. Low, L. Li, A.G. Corfe, P.J. Byrd, "Taper control during percussion drilling of Nimonic alloy using sequential pulse delivery pattern control (SPDPC) ", Proceedings of the ICALEO C, vol. 87, Springer, Berlin, 11-20, (1999).

[24] S. Bandyopadhyay, J.K. Sarin Sundar, G. Sundararajan, S.V. Joshi, "Geometrical features and metallurgical characteristics of Nd:YAG laser drilled holes in thick IN718 and Ti-6Al-4V sheets", Journal of Materials Processing Technology, vol. 127, pp. 83-95, 2002.

[25] G. D. Gautam, A. K. Pandey, "Pulsed Nd:YAG laser beam drilling: A review", Optics \& Laser Technology, vol. 100, pp. 183-215, 2018.

[26] A. Stephen, G. Schrauf, . S. Mehrafsun, F. Vollertsen, "High speed laser micro drilling for aerospace applications", Procedia CIRP, vol. 24, pp. 130-133, 2014.

[27] E. Kannatey-Asibu, Jr., Principles of Laser Materials Processing, John Wiley \& Sons, Inc., Hoboken, USA, 231280p., 361-383p, 2009.

[28] A. Bharatish, H.N. Narasimha Murthyn, G. Aditya, B. Anand, B.S. Satyanarayana, M. Krishna, "Evaluation of thermal residual stresses in laser drilled alumina ceramics using Micro-Raman spectroscopy and COMSOL Multiphysics", Optics \& Laser Technology, vol. 70, pp. 7684, July 2015.

[29] G. H. S. J. S. S. J. S. Badyopadhyay S, "A statistical approach to determine process parameter impact in $\mathrm{Nd}$ :YAG laser drilling of IN718 and Ti-6Al-4V sheets", Optic and Lasers Engineering, vol. 43, p. 163, August 2005.

[30] HP-L-8.9 Laser Scanner Brochure, URL: http://apps.hexagon.se/downloads123/hxmt/romer/H PL89/brochures/HP-L 8.9 brochure en. pdf» Hexagon Metrology, [Erişim zamanı: Ocak, 01 2018].

[31] C. Fry, A. Faulkner, Current concepts in aesthetic and reconstructive oculoplastic surgery, vol. 54, Current Concepts in Aesthetic and Reconstructive Oculoplastic Surgery, pp. 957, 2000. 